\title{
SEISMIC PERFORMANCE OF MASONRY CROSS VAUTS THROUGH SHAKING TABLE TESTING ON A SCALED MODEL
}

\section{N.BIANCHINI ${ }^{*}$, N. MENDES ${ }^{1}$, P. CANDEIAS ${ }^{2}$, M. ROSSI $^{3}$, C. CALDERINI $^{3}$, P.B. LOURENÇO $^{1}$ AND A. CAMPOS COSTA ${ }^{2}$}

${ }^{1}$ Institute for Sustainability and Innovation in Structural Engineering (ISISE) University of Minho

Department of Civil Engineering, Campus de Azurém, 4800-058 Guimarães, Portugal e-mail: nicoletta.bianchini@gmail.com, \{nunomendes, pbl\}@civil.uminho.pt; webpage: www.isise.net (*corresponding author)

${ }^{2}$ National Laboratory for Civil Engineering (LNEC) Department of Structures, Avenida do Brasil, 101, 1700-066, Lisbon, Portugal e-mail: : pcandeias@lnec.pt; webpage: http://www.lnec.pt

${ }^{3}$ Department of Civil, Chemical and Environmental Engineering (DICCA) University of Genoa

Via Montallegro 1, 16145 Genoa, Italy

email: \{chiara.calderini, michela.rossi\}@dicca.unige.it - web page: www.dicca.unige.it

Keywords: Masonry cross vault, Shake table tests, Shear failure, Seismic motions

\begin{abstract}
Masonry cross vaults are among the most widely used typologies of horizontal structural elements for covering spaces of both ordinary and monumental buildings in the European countries. Their seismic vulnerability has been proved by systematic damages and collapses surveyed throughout the centuries. Therefore, the assessment of their structural safety is a crucial issue for the conservation and preservation of historical buildings. Although various methods have been developed and used to analyse both the stability (e.g. equilibrium method) and the dynamic behaviour (e.g. finite and discrete element approaches) of vaulted structures, experimental studies are constantly needed to validate and calibrate models. In this regard, limited experimental studies to understand the dynamic response of vaults have been done. The present paper describes the results of shake table tests on a 1:5 scaled cross vault model made of $3 D$ printed blocks assembled with dry joints, carried out at the $3 D$ LNEC shake table (Portugal). The main aim of the tests is to investigate one of the most typical seismic damage for cross vaults: the shear failure. This type of mechanism frequently affects vaults of lateral aisles and it is mainly caused by a significant difference in stiffness of vaults' supports. Indeed, the lower stiffness of the central nave colonnade compared to the external wall may induce an in-plane shear distortion of the vault caused by a differential longitudinal displacement of its opposite sides. Incremental seismic motions are conducted up to collapse using Emilia Romagna earthquake. The results are analysed in terms crack pattern and damage mechanisms.
\end{abstract}




\section{INTRODUCTION}

Masonry vaults represent one of the most widespread horizontal structural elements in historical buildings. Systematic post-earthquake damage surveys in churches and historical constructions have proved the vulnerability of vaults towards dynamic actions. Although understanding the 3D seismic behaviour of vaults is of primary importance for preserving the cultural heritage, the research in this field is still limited. Most of the works in literature were focused on the 2D analysis of vaults modelled as a sequence of arches, under both static and dynamic actions. Few researchers analysed the 3D behaviour of vaults by simulating seismic actions as differential displacements applied to supports using both numerical and experimental approaches [1]-[3]. The main aim of this paper is to investigate the seismic behaviour of a groin vault with asymmetric boundary conditions, a typical configuration found for example in vaults covering the lateral aisles of the churches or the loggias and porches of palaces [4][5]. During seismic events, especially when the action is mainly acting along the longitudinal direction, the lower stiffness of the central nave's colonnade, compared to the external walls, can lead to differential displacements along the longitudinal direction and, consequently, to the development of a shear damage mechanism in the horizontal structural elements (Figure 1). This failure is mainly identified by typical diagonal crack occurrence, as shown in Figure 1(a) that is recurrently observed during post-earthquake surveys. This is due to the lower stiffness of the central nave's colonnade compared to the external walls can lead to differential displacements along the longitudinal direction and, consequently, the development of a shear

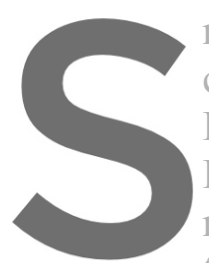
mechanism in the horizontal structurah elements [6]. This pap
campaign on 1:5 scale model of a groin vault tested on the shat
Laboratory for Civil Engineering, Lisbon, Portugal) within SER
Engineering Research Infrastructure Alliance for Europe) Tran
mock-up's geometry and boundary conditions can be representat the lateral nave of a three-nave church (in grey

The shake table tests' results are compared with the results of the quasi-static tests carried

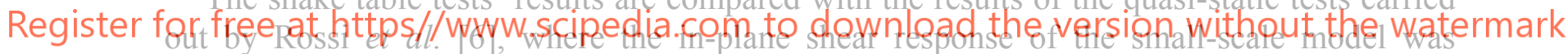

\section{investigated by applying differential displacements on the abutments (Figure 1(b)).}

During the shake tabie tests, the response of the mock-ups was evaluated as function of an increasing intensity earthquake testing protocol, in which a pre-processed strong ground motion component of the Mirandola station (MRN) was used, recorded on May 29, 2012 (Emilia Romagna earthquake).

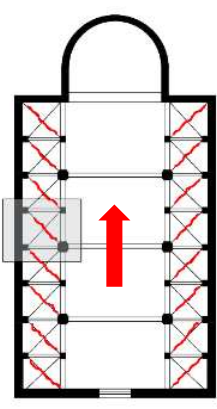

(a)

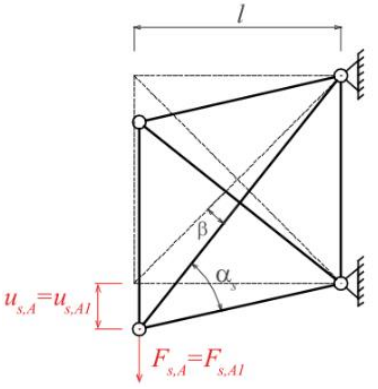

(b)

Figure 1. (a) Typical crack pattern of lateral naves vaults due to the shear mechanism caused by the longitudinal seismic action (red arrow) [7]; (b) simple shear setting studied in [7] and [4]. 


\section{EXPERIMENTAL TESTS}

\subsection{Physical model: geometry of the specimen and material}

The tests were performed on a 1:5 scale model made by 3D printed plastic blocks with dry joints. The same mock-up was already tested under static condition by Rossi et al. [6]. The blocks were 3D printed with the SLS (Selective Laser Sintering) technology: an efficient method to generate small-scale models with high geometrical accuracy $(0.1 \mathrm{~mm})$, low cost and short time of production. Moreover, it allows for the production of blocks with high stiffness (to take into account rigid block assumption and to guarantee the repeatability of the tests by minimizing the damage due to impacts) and high friction (to inhibit sliding between blocks).

The shape and the geometry of the scaled model derived from the intersection of two semicircular barrel vaults, generating a squared base groin vault with a net span of $0.620 \mathrm{~m}$ and a rise of $0.225 \mathrm{~m}$. The model is made up of 1132 blocks (Figure 2a). The standard blocks (red blocks in Figure 2a) were designed considering the typical dimensions of clay bricks, which are $0.06 \times 0.12 \times 0.24 \mathrm{~m}^{3}$ in order to keep a classic bond stereotomy of medieval groin vaults. Blocks of other different dimensions are placed along the outer edges of the webs to guarantee the offset of the joints. Blocks shape is slightly trapezoidal in order to compensate for the absence of mortar between them. Special care was taken to design the stereotomy of the elements located along the diagonals (Figure $2 \mathrm{~b}$ ) to guarantee the correct interlocking between adjacent webs. Each block was identified by a numeric code, in order to easily rebuild the model

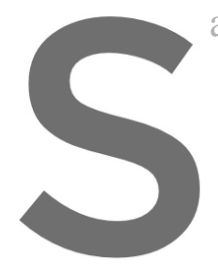
after each test.
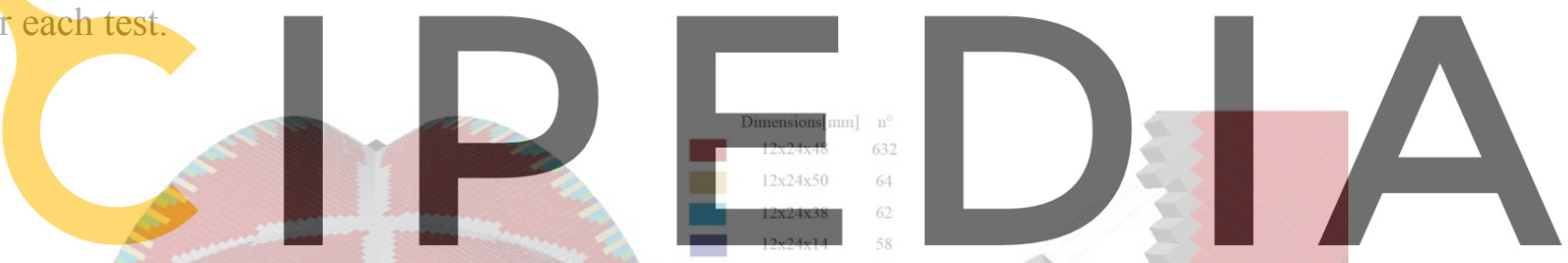

Register for free at https//www.scipedia.com to

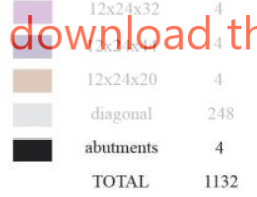

(a)

(b)

Figure 2. Geometry of the small-scale vault and blocks (a); stereotomy of the diagonal blocks (b). [6]

Regarding the stereotomy of masonry brick vaults, the arrangement of the bricks can be varied, as described in Figure 3 [8]. The selected arrangement corresponds to the easiest one to be assembled [4] (Figure 3e). This configuration is called "orthogonal weaving". It directly transfers the thrusts to the supports and it is characteristics of medium and large vaults. However, it needs a temporary timber structure to build the shell of the vault. Therefore, in order to build the model, a temporary supporting structure (scaffolding), made of plywood, has been designed. It consists of four pieces corresponding to the vault webs. Once the model is built, the scaffolding is removed by let the pieces sliding on proper inclined rails, as illustrated in Figure 4. 
The vault's abutments can move freely on a flat surface thanks to four steel plates equipped with some spherical wheels at their extrados. As an alternative, the plate can be anchored to the flat surface by using bolts. The plates are linked to each other by aluminium rods hinged at both ends with uniball joints.

The material density $\rho=0.55 \pm 0.02 \mathrm{~g} / \mathrm{cm}^{3}$ and the friction angle $\mu=39 \pm 2.46^{\circ}$ of the blocks have been determined by testing 12 samples. Since the quite low density of the material could compromise the model stability under accidental actions, the weight of blocks was increased by inserting a steel plate within each of block (Figure 5). The final weight of the whole structure is about $43 \mathrm{~kg}$.

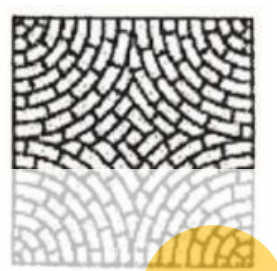

a

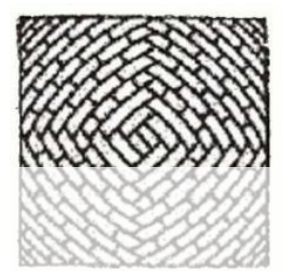

$\mathrm{b}$

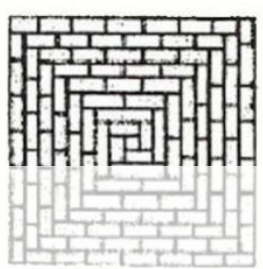

$\mathrm{c}$

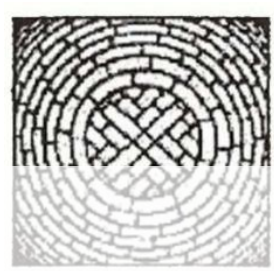

d

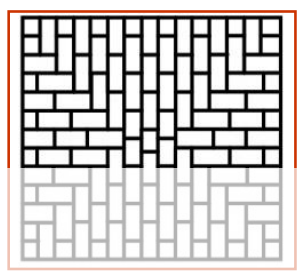

Figure 3. Most common arrangements for masonry cross vaults [8].
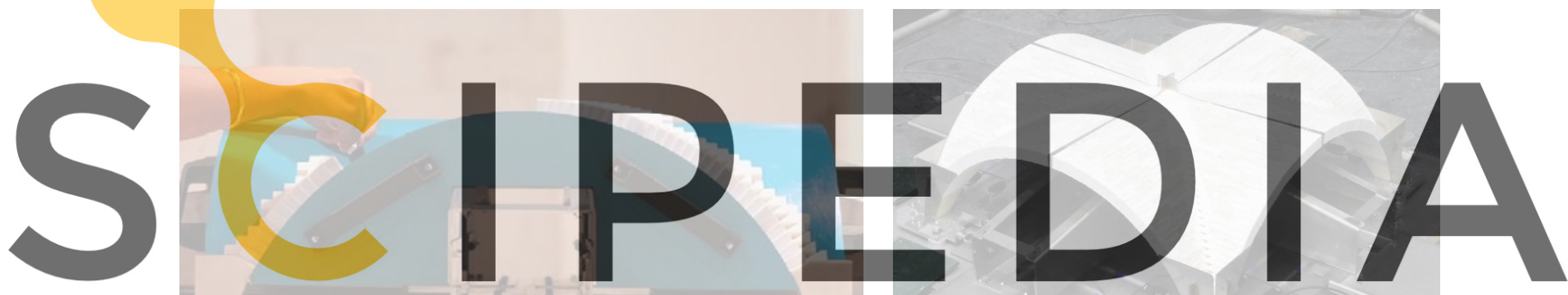

Register for free at https//www.scipedia.com to download the version without the watermark

(a)

(b)

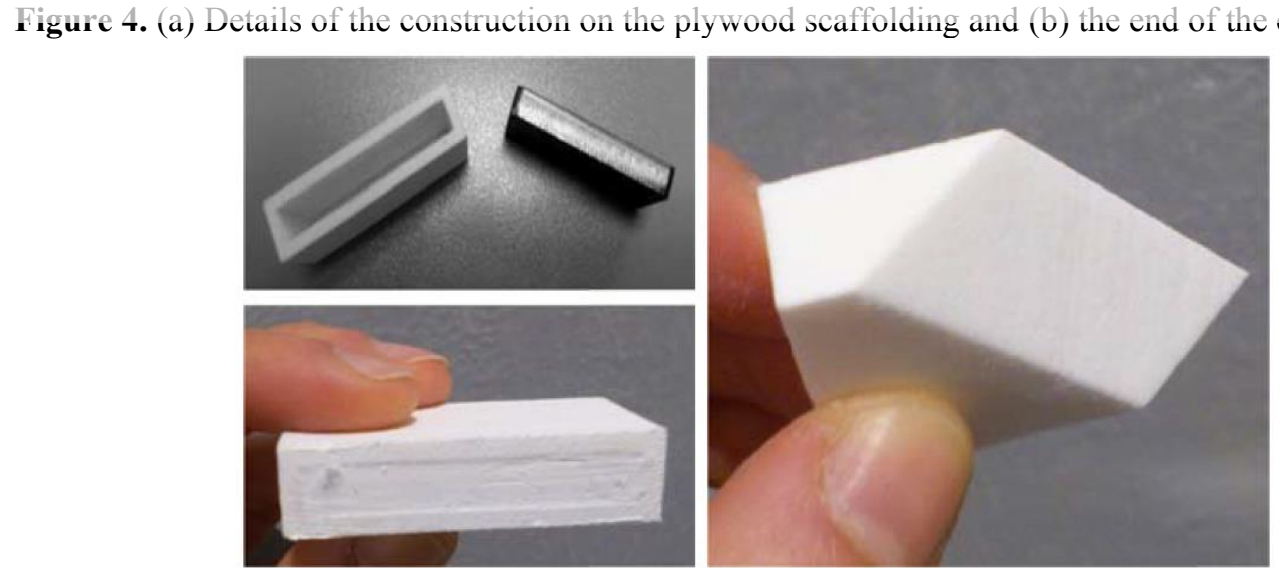

Figure 5. Details of the blocks and of the elements of the diagonals. 


\subsection{Shake table test setup}

The tests were performed at the National laboratory of Civil Engineering in Lisbon (LNEC), which owns a large-scale experimental facility for seismic testing of structures, namely a three axial shake table (Figure 6a). The setup was carefully designed in order to get the most important outputs derived from the induced shear failure on the mock-up, with similar conditions to the real prototypes and measure the relevant effects, which are necessary for the performance assessment (Figure 6b). The abutments $p 1$ and $p 2$ were anchored to the ground with bolts, while $p 3$ and $p 4$ were let free to move on the flat surface.

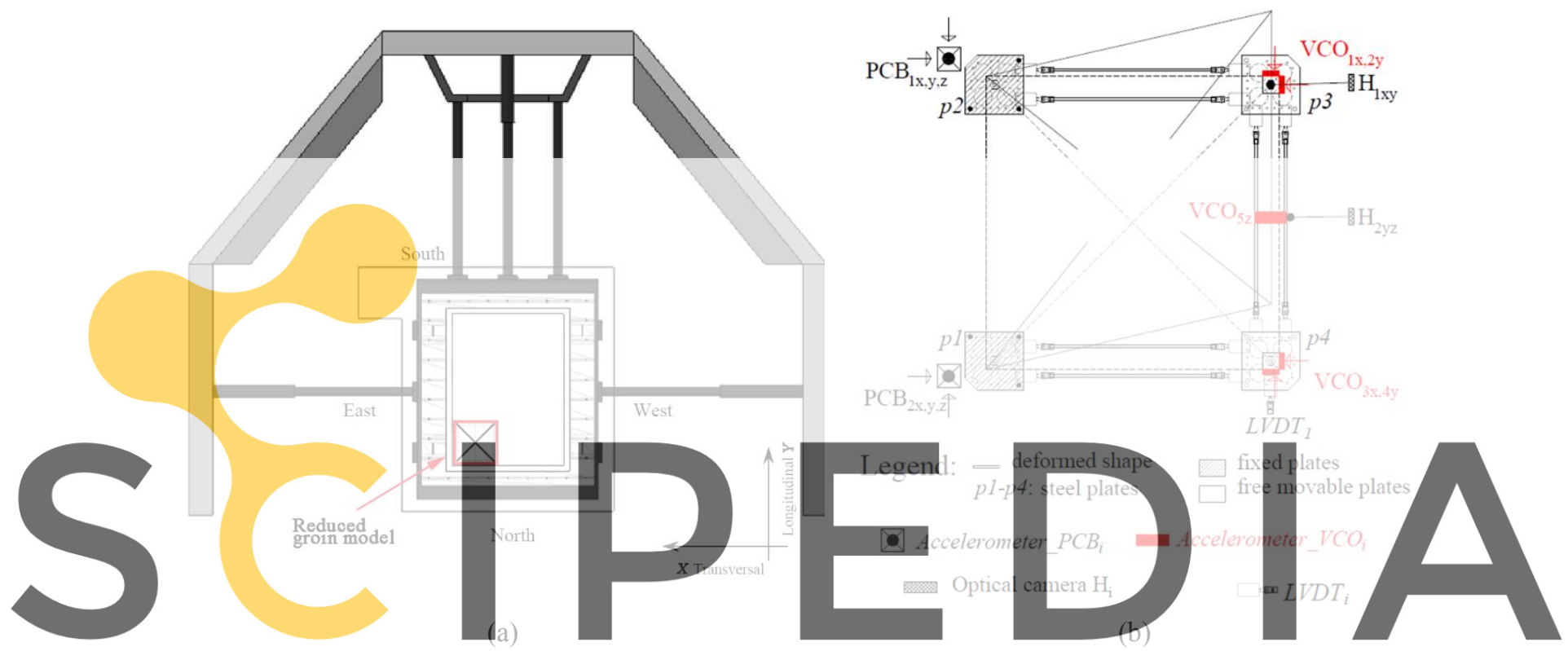

Figure 6. Shaking table: (a) plan.with the location of the model in red; (b) Instrumentation setup: Top view. Register for free at https//www.scipedia.com to download the version without the watermark

The instrumentation of the small-scale groin vault was defined according to the expected behaviour of this kind of mock-up under seismic actions. Therefore, the bases, the movabie plates and the lateral arch (west side) are of interest. Due to the reduced geometrical dimensions of the model, specific equipment was implemented, as referred in Figure 6. One linear variable displacement transducer (LDVT 1$)$, located at the $\mathrm{N}-\mathrm{W}$ corner, measuring the relative longitudinal displacement of the movable piers. Six piezoelectric accelerometers (named $\mathrm{PCB}_{1 \mathrm{x}}, \mathrm{PCB}_{1 \mathrm{y}}, \mathrm{PCB}_{1 \mathrm{z}}, \mathrm{PCB}_{2 \mathrm{x}}, \mathrm{PCB}_{2 \mathrm{y}}, \mathrm{PCB}_{2 \mathrm{z}}$ in Figure $6 \mathrm{~b}$ ) were placed at the bottom of the vault to evaluate the response of the fixed plated, while five variable capacitance unidirectional accelerometers $\left(\mathrm{VCO}_{1 \mathrm{x}}, \mathrm{VCO}_{2 \mathrm{y}}, \mathrm{VCO}_{3 \mathrm{x}}, \mathrm{VCO}_{4 \mathrm{y}}, \mathrm{VCO}_{5 \mathrm{z}}\right)$ were placed on the vault itself, mainly due to the fact that their dimensions and weight are compatible with the dimension of the blocks. Moreover, two optical cameras were used to record the response of the key of the western arch and of the movable piers respectively along the plane $x y\left(\mathrm{H}_{1 \mathrm{xy}}\right)$ and $y z\left(\mathrm{H}_{2 \mathrm{yz}}\right)$.

Two video cameras were placed to record the tests, one exactly at the top of the model using the scaffolding pipes and one located in front of the East façade on a tripod outside of the shake table. From those cameras, the collapse mechanism was evaluated (Section 3). 


\subsection{Dynamic identification tests}

Dynamic identification tests are useful to depict the modal properties of the structure. Dynamic identification techniques can be divided in three main groups: (a) input/output vibration tests, where the excitation applied on the structure and the vibration response are measured; (b) output only vibration tests, where only the vibration response is measured during the service conditions of the structure; (c) free vibration tests, where the structure is forced to an initial deformation and is then quickly released [9]. In this work, only input/output vibration tests were performed.

In the dynamic identification tests, a "pink noise" signal, with large frequency range and low amplitude, was used, aiming at determining the modal parameters for the undamaged and damaged configurations. The duration of this signal is $165 \mathrm{~s}$, with an intense phase of about 60 s. The amplitudes of the inputs were increased, aiming at evaluating the influence of the amplitude of the signal on the dynamic properties. The amplitude of the signals is here defined in terms of nominal displacement. From Figure 7 it is possible to notice that the frequencies range from $3.22 \mathrm{~Hz}$ to $4.5 \mathrm{~Hz}$ for a variation of the amplitude of the signal between $8 \mathrm{~mm}$ and $3 \mathrm{~mm}$, respectively. As expected, the increase of the signal amplitude (nominal displacement) causes a decrease in the frequency of the mock-up. Furthermore, the dynamic identification tests carried out in different days and after different rebuilds of the mock-up present similar frequencies for the same signal amplitude $(5 \mathrm{~mm})$, leading to the conclusion that the mock-up keeps constant the modal frequencies, despite different construction processes or conditions.

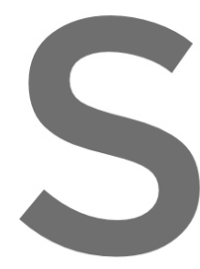
Therefore, its replicability is the results.

\section{Register for free at htt}
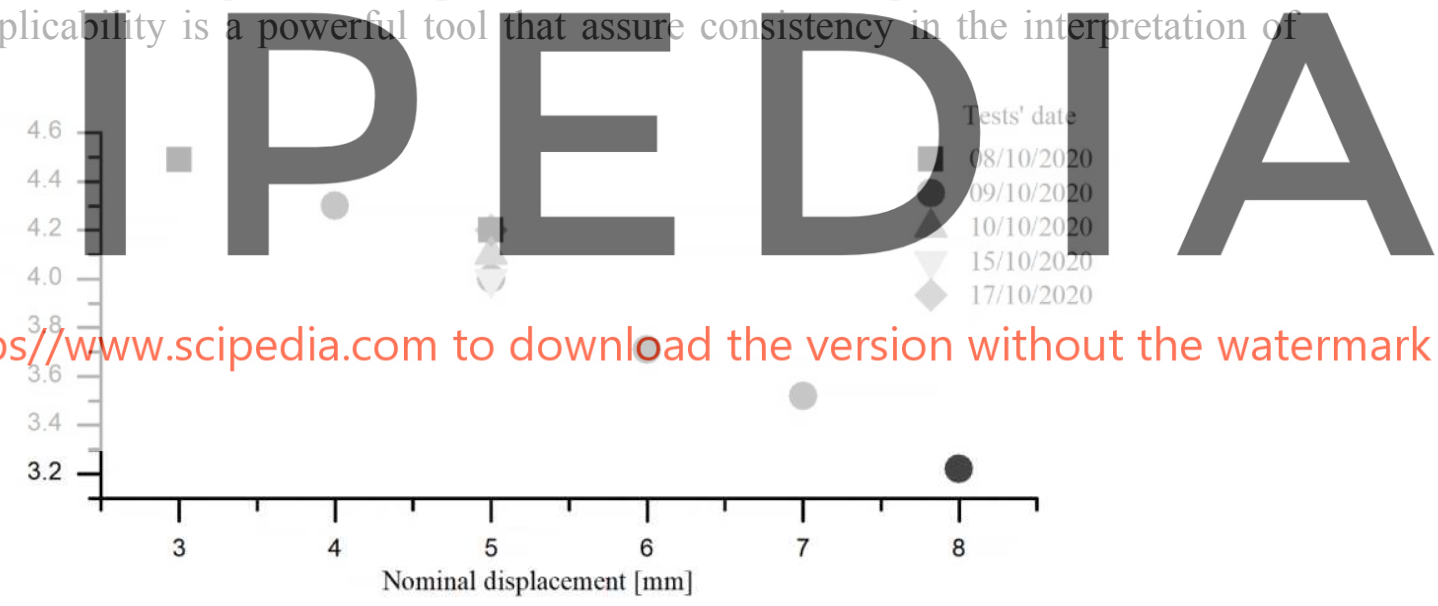

Figure 7. Frequencies as function of the amplitude of signal of the dynamic identification tests.

\subsection{Seismic tests: Emilia earthquake (Mirandola station)}

The Emilia's earthquake was selected for the seismic action, mainly due to the significant presence of masonry groin vaults in the Emilia's Region. In the post-earthquake survey occurred in this region, several cases of shear failures on churches and palaces were observed. Mirandola seismic station (MRN), located $4 \mathrm{~km}$ far from the epicentre, was adopted. It recorded a macro seismic intensity of 7-8 EMS and PGA between $0.27-0.30 \mathrm{~g}$ in the North-South direction (recorded during the main shocks; May $20^{\text {th }}$ and May 29 ${ }^{\text {th }}$, 2012) (Figure 8) [10]. The seismic ground motion, whose entire duration is equal to $30 \mathrm{~s}$, was cut in its intense phase and then filtered, including a baseline correction. 
Figure 8 presents the peak ground-motion parameters, namely the PGA, the peak ground velocity (PGV) and the peak ground displacement (PGD), for each component recorded at the MRN station.

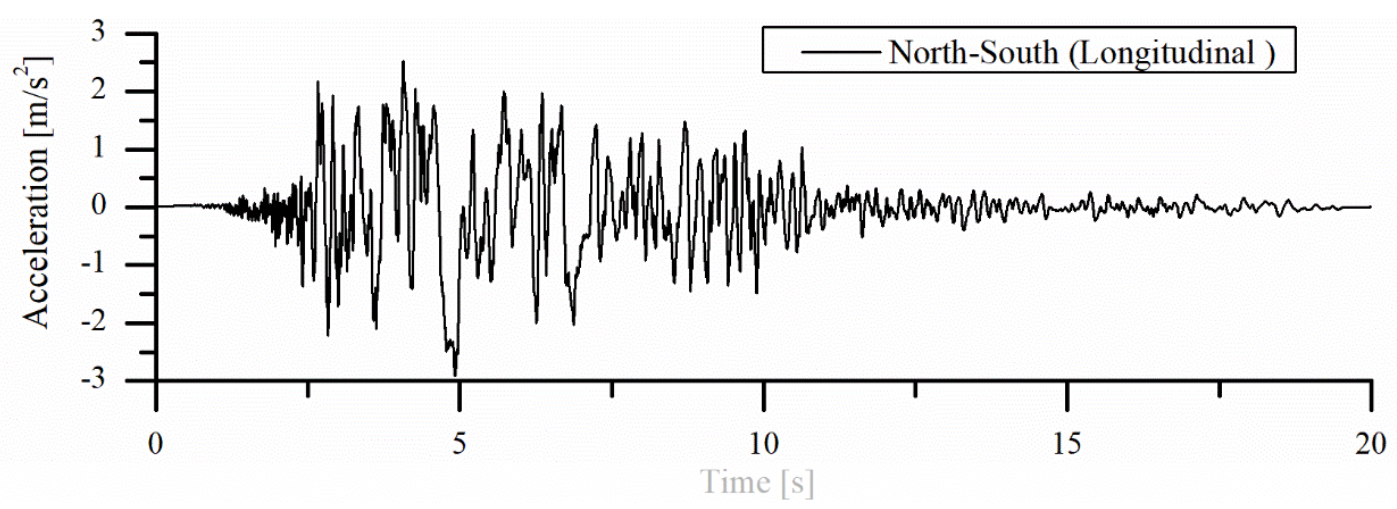

Figure 8. Acceleration time history recorded by Mirandola seismic station along the longitudinal (May $29^{\text {th }}$ )

Table 1: Peak ground-motion parameters for each component recorded at the MRN station (May 29 ${ }^{\text {th }}$ ) [11].

\begin{tabular}{cccc}
\hline & PGA $\left[\mathrm{m} / \mathrm{s}^{2}\right]$ & PGV $[\mathrm{m} / \mathrm{s}]$ & PGD [m] \\
\hline East-West (Transversal) & 0.224 & 0.300 & 0.081 \\
\hline North-South (Longitudinal) & $\mathbf{0 . 2 9 5}$ & $\mathbf{0 . 4 6 3}$ & $\mathbf{0 . 1 0 5}$ \\
\hline
\end{tabular}

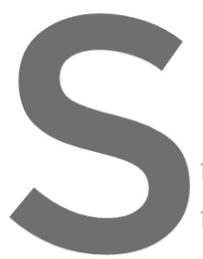

Vertica

In the shake table tests, the

the total duration of 20 s was

total duration of about $9 \mathrm{~s}$.

Table 2 lists the sequence of shake table tests performed on the mock-up with the modal

frequency obtained from input/output dynamic identification tests (DIT), performed before and

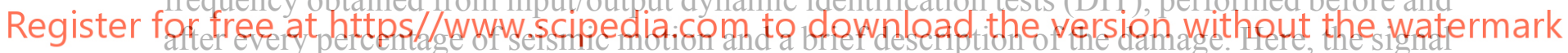

with amplitude equal to $5 \mathrm{~mm}$ was adopted for all the tests. The results shows a maximum frequency reduction, in the last dynamic identification test, of about $21 \%$ (3.22 Hz), with respect to the initial frequency $(4.10 \mathrm{~Hz})$.

For the seismic tests, the spectral acceleration associated to the first period of the reduced scale vault was calculated. The period varies between $0.24-0.25 \mathrm{~s}$, which was obtained from the frequencies obtained by the dynamic identification tests (Table 2).

Table 2. Sequence and brief description of the shake table tests with the reduction of the frequencies.

\begin{tabular}{cccc}
\hline Date & Type of test & Frequency $[\mathrm{Hz}]$ & Description of the damage \\
\hline \multirow{2}{*}{$14 / 01 / 20$} & DIT & 4.10 & Undamaged configuration \\
\cline { 2 - 4 } & Seismic: $10 \%$ & & Middle blocks felt down $\left(\mathrm{n}^{\circ} 2\right)$ \\
\cline { 2 - 4 } & DIT & 4.10 & Middle blocks felt down $\left(\mathrm{n}^{\circ}\right.$ 3) and 1 central steel plate \\
\cline { 2 - 4 } $15 / 01 / 20$ & Seismic: $25 \%$ & & No damage \\
\cline { 2 - 4 } & DIT & 4.00 & Middle blocks felt down $\left(\mathrm{n}^{\circ}\right.$ 3) and 2 central steel plates \\
\cline { 2 - 3 } & Seismic: $50 \%$ & Diagonal $/$ shear failure. \\
& DIT & 3.91 & Sliding in the corners (fixed piers East facade) \\
\hline
\end{tabular}




\begin{tabular}{llcc}
\hline & Seismic: $75 \%$ & & Collapse \\
\hline & DIT & 4.00 & Undamaged configuration \\
\cline { 2 - 4 } & Seismic: $55 \%$ & & Collapse of the centre and sliding of the corner \\
\cline { 2 - 4 } $17 / 01 / 20$ & DIT & 3.42 & No additional damage \\
\cline { 2 - 4 } & Seismic: 25 -Aftershock 1 & East side more damaged \\
\cline { 2 - 4 } & DIT & 3.22 & East side more damaged \\
\cline { 2 - 3 } & Seismic: 35 -Aftershock 2 & & Collapse \\
\hline
\end{tabular}

Figure 9 presents the spectral acceleration for each seismic action applied during the sequence of tests (Table 2). In comparison with the quasi static tests performed by Rossi et.al [6] and also with the numerical analyses carried out by Gaetani et al. [12] (dot line in Figure 9), the results obtained from the shake table tests show that the same model can resist about 1.5 times more under dynamic actions than static ones.

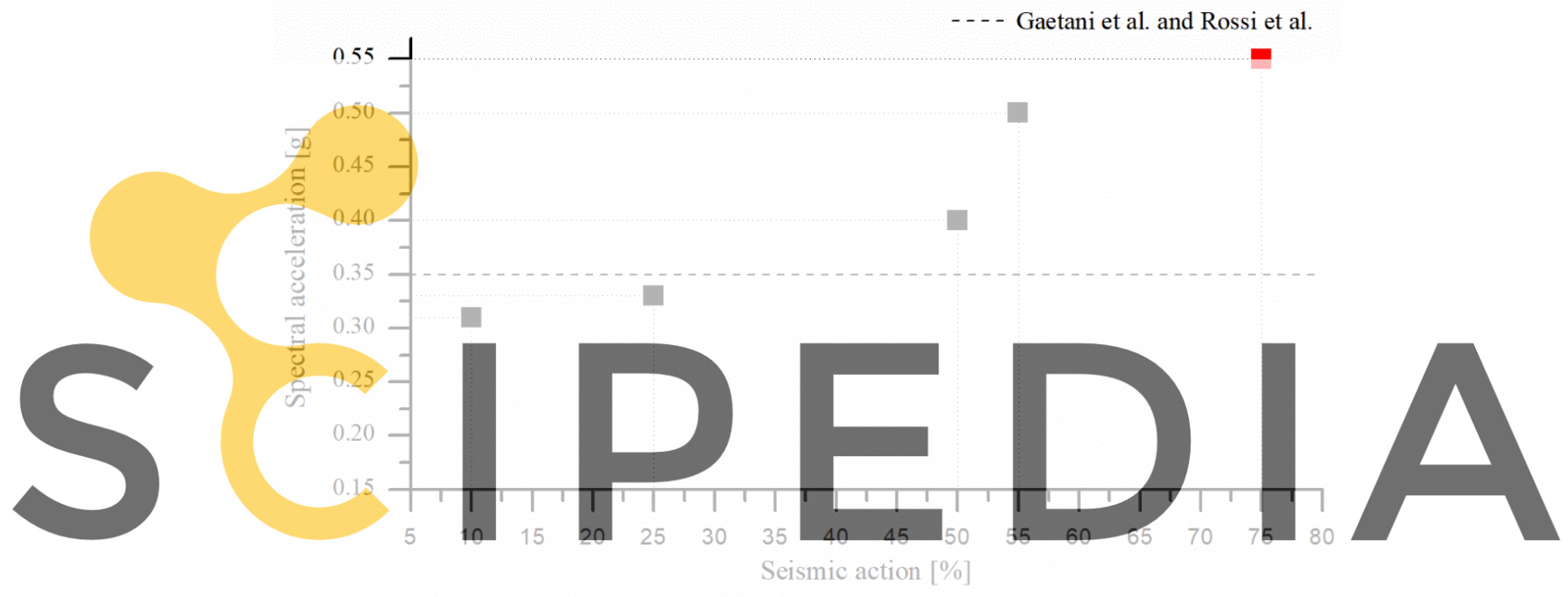

Register for free at https//www.scipedia.com to download the version without the watermark Figure 9. Spectral acceleration as function of seismic actions (no-aftershocks). (Red color corresponds to the collapse).

\section{EVALUATION OF THE COLLAPSE MECHANISM}

As previously mentioned, the shake table tests involved several seismic tests with different amplitude. In this Section, the collapse mechanism obtained for the $75 \%$ of the Mirandola earthquake applied in the longitudinal direction (from North to South, Figure 6) is evaluated. The collapse mechanism is discussed using a sequence of photos, where the number and locations of the hinges is also evaluated. Figure 10 presents the more intense phase before the collapse of the vault, recording five frames per second, with the camera placed at the top of the central key of the model.

The centre of the vault is the first to collapse, due to geometrical configuration. The fall of the blocks at centre of the vault do not interfere with the shear failure, which is the first to occur at $2 \mathrm{~s}$ while the hinges are starting to appear. The external edges (North and West side) continue to stand, even when the other sides already felt down. The location of the hinges was observed 
from the East façade, where it is possible to notice the similarities with the quasi-static tests (Figure 11).

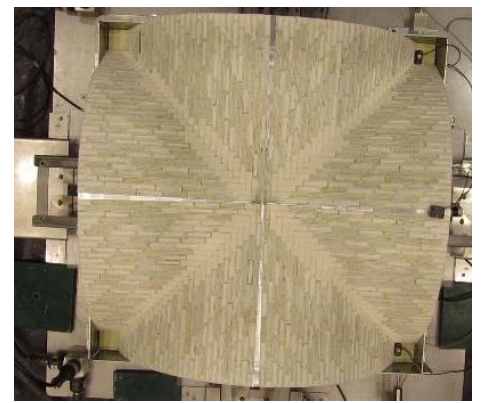

$1 \mathrm{~s}$
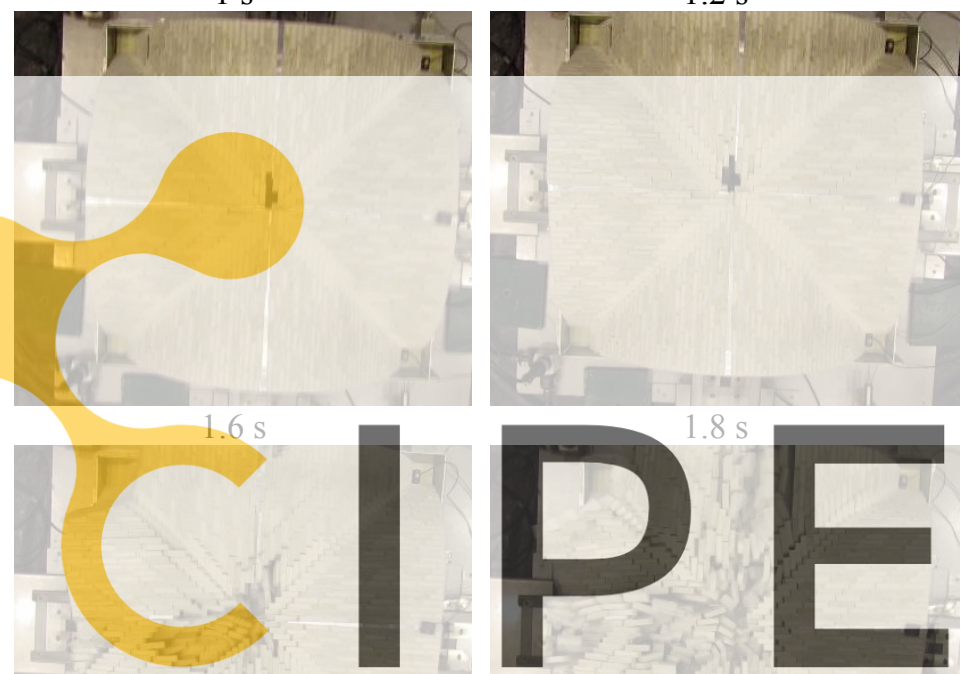

Register for free at https//www.scipedia.com to downloa

$$
2.2 \mathrm{~s}
$$

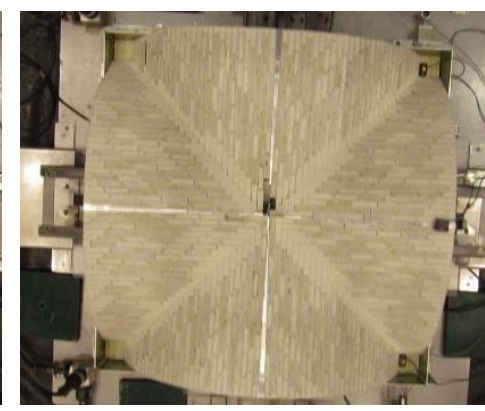

$1.4 \mathrm{~s}$
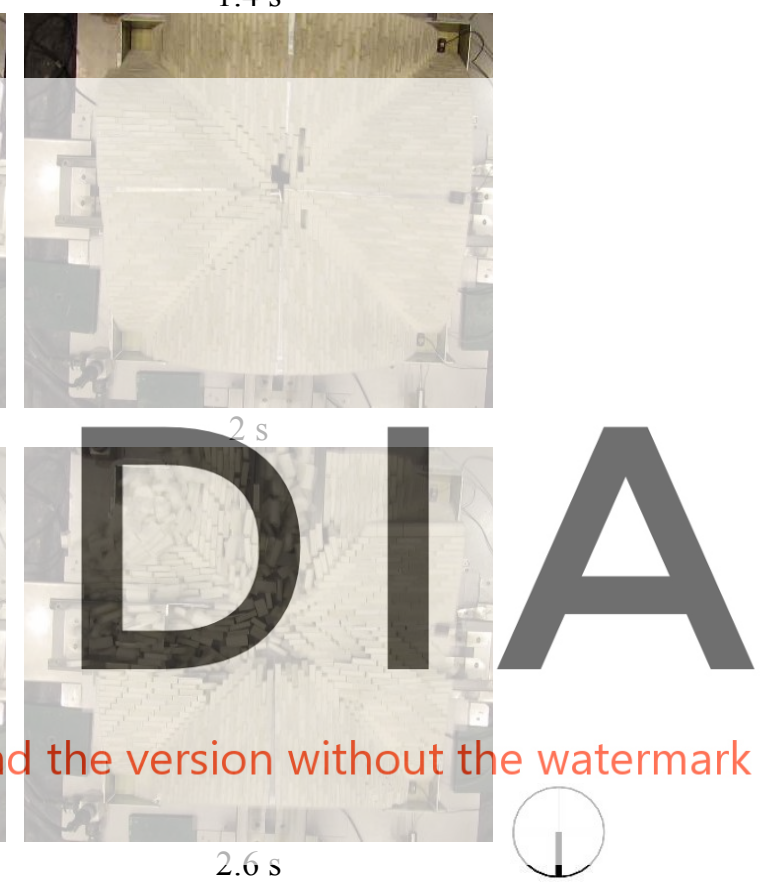

Figure 10. Damage progression of the mock-up during the intense phase of the seismic input $75 \%(5$ frames/s). (Left side: fixed supports; right side: movable supports).

The steel plates at the corners make the boundaries of the shell of the vault stiffer and, therefore, two hinges take location where the steel plates do not act anymore. This is in agreement with the prediction of Oppenheim and De Lorenzis et al. [13], [14], based on the minimum energy formulations. The arch mechanism is clear (four hinges) and it is mainly associated to the edge side where the supports are fixed and the response is more rigid (Figure 11). 


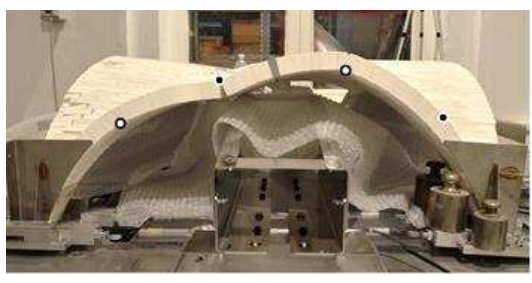

(a)

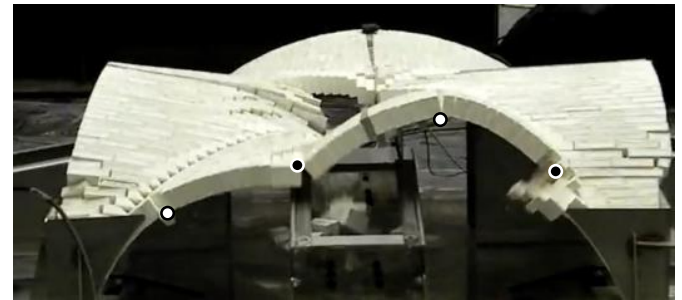

(b)

Figure 11. Comparison between the quasi-static [6] (a) and the shake table tests (b).

\section{CONCLUSIONS}

This paper presents the first study on the behaviour of a brick masonry groin vault, namely the first set of shake table tests. The tests aim at evaluating the shear failure of a vault composed by 3D printed blocks and built at 1:5 scaled model with dry joints, previously used also in quasistatic tests. The shake table tests involved dynamic identification tests and seismic tests, where the 2012 Emila's Earthquake recorded in Mirandola station was adopted.

The dynamic identification tests allowed to evaluate the variations on modal properties of the model as function of the construction process and amplitude of the seismic action. The results of the shake table tests were evaluated and compared with the quasi-static tests, leading to the following conclusions: (a) the location of the hinges is similar and there are more clear

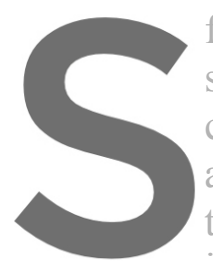
from the side where the showing, as expected, capacity of the structure about 1.5 times, showing a spectral amplitude at this value corresponds to the base of the vault
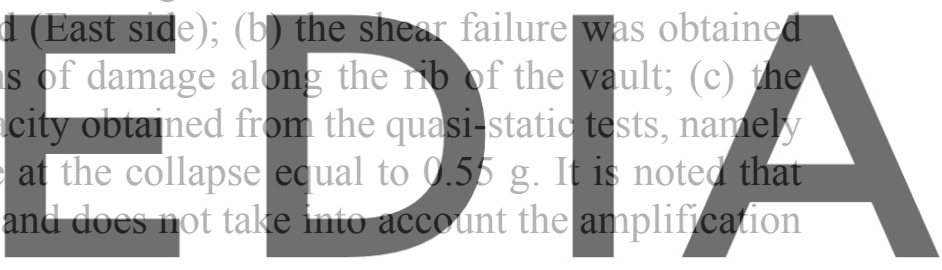
in elevation on the structure.

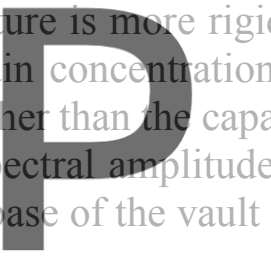

Further investigations should carried out, namely for other types of seismic motions, such

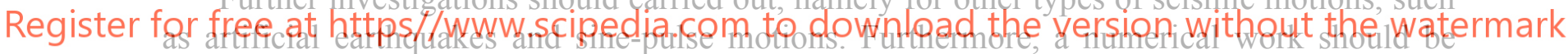
performed, aiming at validating the results obtained in the tests and evaluating the response of brick masonry groin vauit taking into account the dispersion on their features.

Acknowledgements. The authors are grateful to the National Laboratory of Civil Engineering for providing the experimental data for the shaking table tests. This work was partly financed by FCT - Foundation for Science and Technology within the scope of the project "Seismic Response of Masonry Cross Vaults: Shaking table tests and numerical validations" and the $\mathrm{PhD}$ grant SFRH/BD/136831/2018.

\section{REFERENCES}

[1] P. Block, T. Ciblac, and J. A. Ochsendorf, 'Real-time limit analysis of vaulted masonry buildings', Comput. Struct., vol. 84, no. 29-30, pp. 1841-1852, Nov. 2006.

[2] G. Milani and A. Tralli, 'A simple meso-macro model based on SQP for the non-linear analysis of masonry double curvature structures', International Journal of Solids and Structures, vol. 49, no. 5. pp. 808-834, 2012. 
[3] B. Torres, E. Bertolesi, J. J. Moragues, P. A. Calderón, and J. M. Adam, 'Experimental investigation of a full-scale timbrel masonry cross vault subjected to vertical settlement', Constr. Build. Mater., vol. 221, pp. 421-432, 2019.

[4] M. Rossi, 'Evaluation of the Seismic Response of Masonry Cross Vaults', Università degli Studi di Genova, 2015.

[5] F. Giovanetti, Manuale del recupero del Comune di Città di Castello. Rome (in Italian): DEI, 2000.

[6] M. Rossi, C. Calderini, and S. Lagomarsino, 'Experimental testing of the seismic inplane displacement capacity of masonry cross vaults through a scale model', Bull. Earthq. Eng., vol. 14, no. 1, pp. 261-281, 2016.

[7] N. Bianchini, N. Mendes, P. B. Lourenço, C. Calderini, and M. Rossi, 'Seismic assessment of masonry cross vaults through numerical nonlinear static and dynamic analysis', in COMPDYN 2019 7th ECCOMAS Thematic Conference on Computational Methods in Structural Dynamics and Earthquake Engineering, 2019, no. I, pp. 600-612.

[8] A. Raimondi, 'La chiesa di Santa Maria in Scaria. Gestire la complessità: dal rilievo al BHIM.', 2013.

[9] L. F. Ramos, 'Damage Identification on Masonry Structures Based on Vibration Signatures', Universidade do Minho, 2007.

[10] A. Penna, P. Morandi, M. Rota, C. Filippo, and P. Guido, 'Performance of masonry buildings during the Emilia 2012 earthquake', Bull. Earthq. Eng., pp. 2255-2273, 2014.

[11] F. Bozzoni, C. G. Lai, and L. Scandella, 'Preliminary results of ground-motion characteristics', Ann. Geophys., vol. 55, no. 4, pp. 609-614, 2012.

[12] A. Gaetani, N. Bianchini, and P. B. Lourenço, 'Simplified micro-modelling of masonry cross vaults: stereotomy and interface issues', Int. J. Mason. Res. Innov., p. Accepted manuscript, 2019.

[13] I. J. Oppenheim, 'The masonry arch as a four-link mechanism under base motion', Earthq. Eng. Struct. Dyn., vol. 21, no. 11, pp. 1005-1017, 1992.

[14] L. De Lorenzis, M. J. Dejong, and J. A. Ochsendorf, 'Failure of masonry arches under impulse base motion', Earthq. Eng. Struct. Dyn., vol. 36, no. 14, pp. 2119-2136, Nov. 2007. 